\title{
Mudanças no uso da terra e o particionamento de energia no sudoeste da Amazônia
}

\author{
Alberto D. Webler' ${ }^{1}$ Josiane B. Gomes ${ }^{2}$, Renata G. Aguiar ${ }^{3}$, \\ Nara L. R. de Andrade ${ }^{4}$ \& Leonardo J. G. Aguiar ${ }^{5}$
}

\begin{abstract}
RESUMO
A expressiva taxa de desmatamento na região amazônica tem se tornado uma preocupação mundial. Este processo consiste, substancialmente, na conversão de sistemas florestais em sistemas agropecuários. Este novo ecossistema requer estudos que elucidem quanto ao seu funcionamento buscando o entendimento de como a referida região interage com a atmosfera. Com o intento de investigar o comportamento de componentes do balanço de energia em uma área de pastagem foi realizado um estudo na Fazenda Nossa Senhora, no município de Ouro Preto do Oeste, Rondônia, buscando-se analisar os padrões da radiação líquida e dos fluxos de calor latente, sensível e no solo, nos períodos: úmido, úmido-seco, seco e seco-úmido, nos anos de 2000 a 2005. As medidas dos fluxos de calor latente e sensível foram realizadas utilizando-se o método de covariância de vórtices turbulentos. Os resultados dessas análises evidenciaram que o particionamento de energia em uma área de pastagem nos períodos úmido, úmido-seco, seco e seco-úmido foram, respectivamente, de 77,$8 ; 69,6 ; 50,6$ e 75,2\% para o fluxo de calor latente e 22,5; 31,2; 46,7 e 24,7\% para o fluxo de calor sensível, indicando uma vulnerabilidade maior da pastagem às alterações sazonais.
\end{abstract}

Palavras-chave: pastagem, fluxos de energia, correlação de vórtices turbulentos

\section{Changes in land use and energy partitioning in the southwest of the Amazon}

\begin{abstract}
The significant rate of deforestation in the Amazon region has become a global concern. This process consists substantially in the conversion from forest to agricultural systems, which is the activity that drives the local economy. This new ecosystem formed requires studies that elucidate its operation, seeking to understand how this region interacts with the atmosphere. To investigate the behavior of energy balance components in a grassland ecosystem, a study was conducted at Fazenda Nossa Senhora (FNS), in Ouro Preto do Oeste, Rondônia. This study examined net radiation and sensible, latent and soil heat fluxes patterns, in the periods: wet, wet-dry, dry and dry-wet from 2000 to 2005 . Measurements of sensible and latent heat fluxes were performed using the eddy covariance method. The results of these analyses showed that the partitioning of energy in the grassland were $77.8,69.6,50.6$ and $75.2 \%$, respectively in the wet, wet-dry, dry and dry-wet periods, for the latent heat flux and 22.5, 31.2, 46.7 and $24.7 \%$ for the sensible heat flux, indicating a higher vulnerability of grassland to seasonal changes.
\end{abstract}

Key words: grassland, energy fluxes, eddy correlation

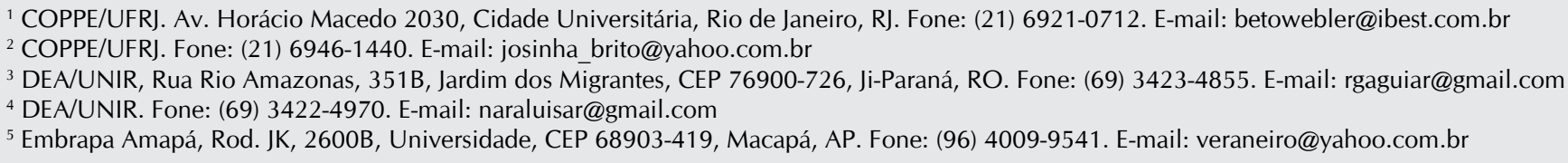




\section{INTRODUÇÃO}

A expansão agrícola e da pecuária ocorre dentro de um contexto econômico uma vez que há uma relação direta entre os indicadores econômicos, como Produto Interno Bruto (PIB) e o aumento de áreas convertidas (Ewers et al., 2008). A forma mais presente e detectável de mudanças do uso da terra na Amazônia tem sido a conversão de florestas de dosseis fechados em campos de pastagens e de cultivos, comprometendo a fertilidade do solo em decorrência dos longos períodos de monocultura (Correia, 2006).

Essas contínuas e crescentes alterações no cenário amazônico podem acarretar modificações em diversos processos como, por exemplo, na formação das nuvens que têm suas propriedades microfísicas alteradas em decorrência da emissão de grandes quantidades de partículas que atuam como núcleos de condensação. Artaxo et al. (2005) ponderam que tais mudanças nas nuvens podem estar alterando o padrão de precipitação na região e, consequentemente, modificando todo o ciclo hidrológico.

Em contrapartida, a pecuária é a principal força motora da economia local e regional em que, de acordo com dados da Agência de Defesa Sanitária Agrossilvopastoril do Estado de Rondônia (IDARON, 2008), Rondônia foi o oitavo maior produtor de carne bovina do País em 2008 exportando, anualmente, cerca de $70 \%$ de sua produção num total de $480 \mathrm{t}$ de carne bovina, o que resulta em um crescimento econômico e, em consequência, na rápida expansão de pastagens em detrimento das florestas tropicais.

Pesquisas no âmbito do programa LBA (experimento de grande escala da biosfera-atmosfera na Amazônia) são dirigidas para este entendimento, de como a Amazônia está mudando em função do crescimento econômico. Tais pesquisas buscam entender como a mudança do uso do solo afeta o clima local e global, a biota, os processos químicos e físicos, bem como a sustentabilidade do desenvolvimento na região (Keller et al., 2004).

De forma a contribuir para a diminuição dos impactos ambientais são imprescindíveis estudos que elucidem quanto ao funcionamento desse ecossistema, buscando o entendimento de como esta região interage com a atmosfera. As características do equilíbrio energético de muitos tipos decobertura do solo devem ser esclarecidas não apenas por estudos de modelagem mas também por estudos observacionais in situ (Tanaka et al., 2008) o que pode contribuir para o desenvolvimento de modelos mais eficientes e com maior grau de confiabilidade.

São poucas as referências acerca do comportamento do balanço de energia em áreas de pastagens durante as diferentes estações do ano e seus períodos de transição, apesar da sua utilização na identificação do consumo hídrico de culturas.

Neste sentido, o presente estudo buscou evidenciar o comportamento dos componentes do balanço de energia: radiação líquida, fluxos de calor latente, sensível e no solo, nos períodos úmido, úmido-seco, seco e seco-úmido, mostrando a sazonalidade, o fechamento do balanço de energia e alguns fatores intermitentes de sua variação nos anos de 2000 a 2005 em uma área de pastagem no sudoeste da Amazônia; apesar disto, tal análise pode auxiliar na redução da incerteza das previsões ou projeções futuras da mudança climática global.

\section{Material e Métodos}

As medidas foram realizadas durante os anos de 2000 a 2005 em um sítio experimental pertencente à rede de torres micrometeorológicas do Programa LBA, em Rondônia. O sítio experimental está localizado na Fazenda Nossa Senhora (FNS), nas coordenadas $10^{\circ} 45^{\prime} \mathrm{S}$ e $62^{\circ} 22^{\prime} \mathrm{W}$, altitude de 293 m, no município de Ouro Preto do Oeste (Figura 1). O período úmido é característico de janeiro a março, úmido-seco de abril a junho, seco de julho a setembro e seco-úmido de outubro a dezembro, com precipitação média anual de $1627 \mathrm{~mm}$.

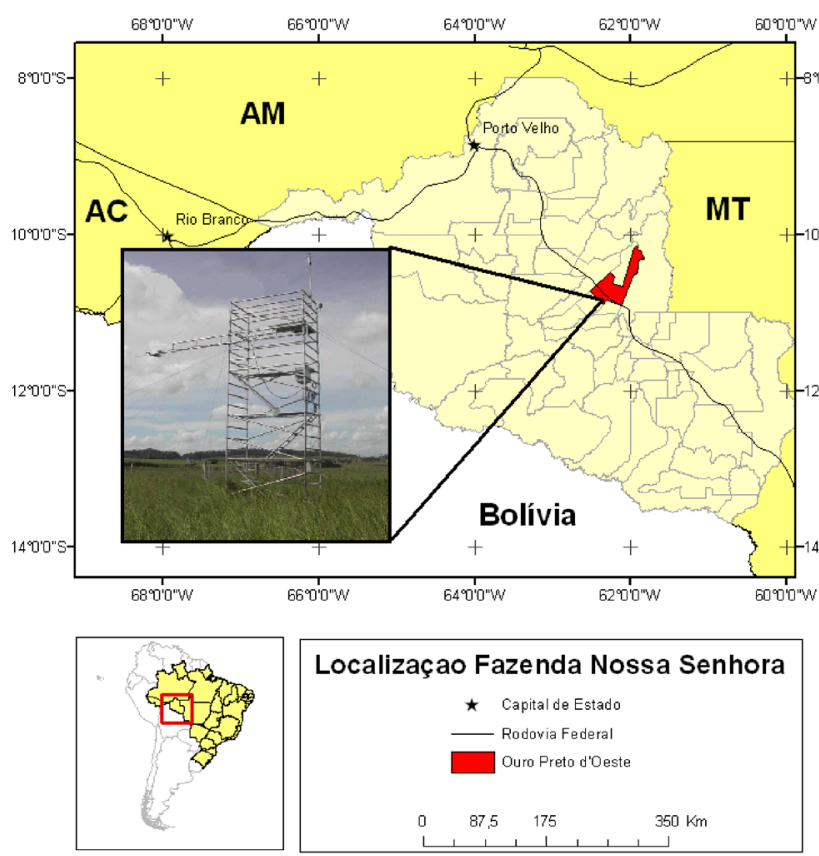

Figura 1. Estação micrometeorológica do Programa LBA, Ouro Preto do Oeste, Rondônia

Inicialmente, a área estudada foi desflorestada por meio do fogo em 1971 e desde 1991 foi considerada área com predominância da gramínea Brachiaria brizantha. O fetch no sítio experimental é de aproximadamente 1 a $2 \mathrm{~km}$, em todas as direções (Randow et al., 2004).

As medidas dos fluxos de calor latente (LE) e sensível (H) foram obtidas por um sistema de alta frequência dos fluxos de superfície, composto por um anemômetro sônico tridimensional (Solent 1012R2, Gill Instruments, UK) e um analisador de gás por infravermelho de caminho fechado (IRGA, Li-6262, LICOR, USA). Esses sensores estavam conectados a um microcomputador tipo "palmtop" que fazia as leituras dos sensores com uma frequência de $10 \mathrm{~Hz}$ e armazenava os dados brutos em arquivos, a cada $30 \mathrm{~min}$.

Os dados brutos contendo as flutuações em alta frequência dos componentes da velocidade do vento, medidos pelo anemômetro sônico, e da concentração de vapor d'água, medidos pelo IRGA, foram processados em um computador com auxílio do software Alteddy (Elbers, 1998). Este programa foi desenvolvido pela Alterra Green World Research e se destina a obter os fluxos turbulentos de energia (fluxo de $\mathrm{H}$ e LE) através do sistema de correlação de vórtices turbulentos (Eddy Correlation), por meio da aplicação das Eqs. 1 e 2. 


$$
\begin{aligned}
& L E=p \hat{w} \cdot q \cdot \\
& H=p c_{p} w \cdot T \cdot
\end{aligned}
$$

em que:

$$
\begin{array}{ll}
\mathrm{p} & \text { - densidade do ar, } \mathrm{kg} \mathrm{m}^{-3} \\
\chi & \text { - calor latente de evaporação, } \mathrm{J} \mathrm{kg}^{-1} \\
\mathrm{q} & \text { - umidade específica, } \mathrm{kg} \mathrm{kg}^{-1} \\
\mathrm{c}_{\mathrm{p}} & \text { - calor específico do ar, } \mathrm{J} \mathrm{kg}^{-1} \mathrm{~K}^{-1} \\
\mathrm{~T} & \text { - temperatura do ar, }{ }^{\circ} \mathrm{C}
\end{array}
$$

A umidade específica do ar foi calculada a partir da Eq. 3 e a umidade específica de saturação pela Eq. 4. A temperatura e umidade do ar foram coletadas utilizando o termohigrômetro HMP45D (Vaisala Inc., FIN) e o sensor de pressão PTB100 (Vaisala Inc., FIN):

$$
\begin{gathered}
q=\frac{0,622 e}{P-0,378 e} \\
q_{s}=\frac{0,622 e_{s}}{P-0,378 e_{s}} \times 1000
\end{gathered}
$$

em que:

$$
\begin{array}{ll}
\mathrm{q} & \text { - umidade específica, } \mathrm{kg} \mathrm{kg}^{-1} \\
\mathrm{e} & \text { - pressão atual do vapor d'água, } \mathrm{hPa} \\
\mathrm{P} & \text { - pressão atmosférica, } \mathrm{hPa} \\
\mathrm{q}_{\mathrm{s}} & \text { - umidade específica de saturação, } \mathrm{g} \mathrm{kg}^{-1} \\
\mathrm{e}_{\mathrm{s}} & \text { - pressão de saturação do vapor d'água, } \mathrm{hPa}
\end{array}
$$

A radiação líquida foi calculada através da Eq.5 e as radiações de onda curta de forma incidente e refletida, foram medidas pelos piranômetros CM21 (Kipp \& Zonen, Delft, NLD), com intervalo espectral de 305 a $2800 \mathrm{~nm}$. A radiação de onda longa foi medida através de dois pirgeômetros CG1 (Kipp \& Zonen, Delft, NLD) de forma incidente (atmosférica) e emitida pela superfície com intervalo espectral de 4500 a $42000 \mathrm{~nm}$. O fluxo de calor no solo (G) foi medido a $1 \mathrm{~cm}$ da superfície do solo por meio do sensor SH1 (Flux plates, Hukseflux, NLD).

Os dados utilizados foram coletados e armazenados pelo datalogger CR10X (Campbell Scientific Instrument, USA), com medidas a cada $30 \mathrm{~s}$ e médias a cada $10 \mathrm{~min}$.

$$
\mathrm{R}_{\text {_liq }}=\left(\mathrm{S}_{\text {in }}-\mathrm{S}_{\text {out }}\right)+\left(\mathrm{L}_{\text {in }}-\mathrm{L}_{\text {out }}\right)
$$

\begin{tabular}{|c|c|c|}
\hline Medidas & Instrumento & Altura (m) \\
\hline$S_{\text {in }}$ e $S_{\text {out }}$ & $\begin{array}{l}\text { Piranômetros CM21 (Kipp \& } \\
\text { Zonen) }\end{array}$ & 6,5 \\
\hline$L_{\text {in }}$ e $L_{\text {out }}$ & $\begin{array}{l}\text { Piranômetros CG1 (Kipp \& } \\
\text { Zonen) }\end{array}$ & 6,5 \\
\hline G & SH1 - Flux plates (Hukseflux) & 0,01 \\
\hline T e UR & $\begin{array}{l}\text { Termohigrômetro HMP45D } \\
\text { (Vaisala) }\end{array}$ & 8,3 \\
\hline VV & $\begin{array}{l}\text { Anemômetro a 100R } \\
\text { (Vector) }\end{array}$ & 9,3 \\
\hline$P$ & Pluviômetro (EM, ARG100) & 0,5 \\
\hline $\begin{array}{l}\text { Velocidade do vento, } \\
\text { temperatura, } \mathrm{H}_{2} \mathrm{O} \text { e } \\
\text { concentração de } \mathrm{CO}_{2}\end{array}$ & $\begin{array}{l}\text { Anemômetro sônico } \\
\text { tridimensional (Gill) e IRGA } \\
\text { (LICOR, 6262) }\end{array}$ & 4,0 \\
\hline Pressão atmosférica & Barômetro (PTB100, Vaisala) & 5,4 \\
\hline
\end{tabular}

em que:

$\mathrm{R}$ _liq - radiação líquida, $\mathrm{W} \mathrm{m}^{-2}$

$\mathrm{S}_{\text {in }}$ e $\mathrm{S}_{\text {out }}$ - radiação de onda curta incidente e refletida, respectivamente, $\mathrm{W} \mathrm{\textrm {m } ^ { - 2 }}$

$\mathrm{L}_{\text {in }}$ e $\mathrm{L}_{\text {out }}$ - radiação de onda longa atmosférica e terrestre, respectivamente, $\mathrm{W} \mathrm{m} \mathrm{m}^{-2}$

Filtragens nos dados foram efetuadas utilizando-se valores mínimos, máximos e de diferenças entre as médias, préestabelecidos e utilizados por Randow et al. (2004), de forma a eliminar os dados espúrios. A lista de medidas, instrumentos e respectivas alturas, estão apresentados na Tabela 1 .

Tabela 1. Lista de medidas, instrumentos e respectivas alturas da estação automática e do sistema eddy correlation instalados na FNS

\section{Resultados e Discussão}

Durante o período de observações a fazenda FNS apresentou um padrão sazonal bem definido (Figura 2), sendo que a precipitação da estação chuvosa correspondeu a 44\% (715 $\mathrm{mm}$ ) do total anual e a da estação seca correspondeu a apenas $10 \%$ (168 mm). Os valores aqui apresentados são similares aos encontrados por Costa et al. (1998) e Webler et al. (2007) na mesma área em estudo.

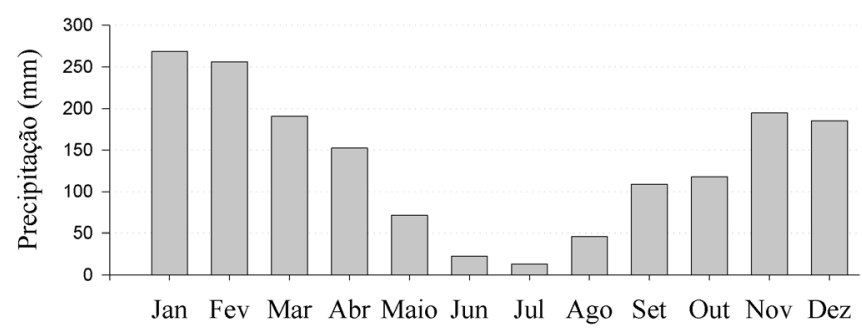

Figura 2. Média do total mensal da precipitação nos anos de 2000 a 2005

O padrão da precipitação se deve parcialmente às características locais uma vez que cerca de $50 \%$ do balanço de vapor d'água são mantidos pela evapotranspiração local e outro fator relevante é a relação entre a precipitação e a cobertura de nuvens altas na escala mensal na região (Machado et al., 2004; Dias et al., 2005).

Os padrões sazonais da velocidade do vento e da temperatura do ar estão apresentados na Figura 3. A velocidade do vento a 9,3 m apresentou, no mês de fevereiro, a maior média, $2,78 \pm 0,43 \mathrm{~m} \mathrm{~s}^{-1}$ (todo valor após o sinal \pm corresponde a um intervalo de confiança da média de $95 \%$ ), e menor média no mês de junho, com 2,11 $\pm 0,46 \mathrm{~m} \mathrm{~s}^{-1}$, que corresponde ao final do período úmido-seco. Durante o período úmido a média da velocidade do vento foi cerca de $10 \%$ maior em relação ao seco (Figura 3A).

A temperatura do ar apresentou média anual de 24,8 $\pm 0,9$ ${ }^{\circ} \mathrm{C}$ com temperatura mínima de $10,11{ }^{\circ} \mathrm{C}$ no mês de julho e valores máximos de $37,92^{\circ} \mathrm{C}$ em abril (Figura 3B). Em termos 


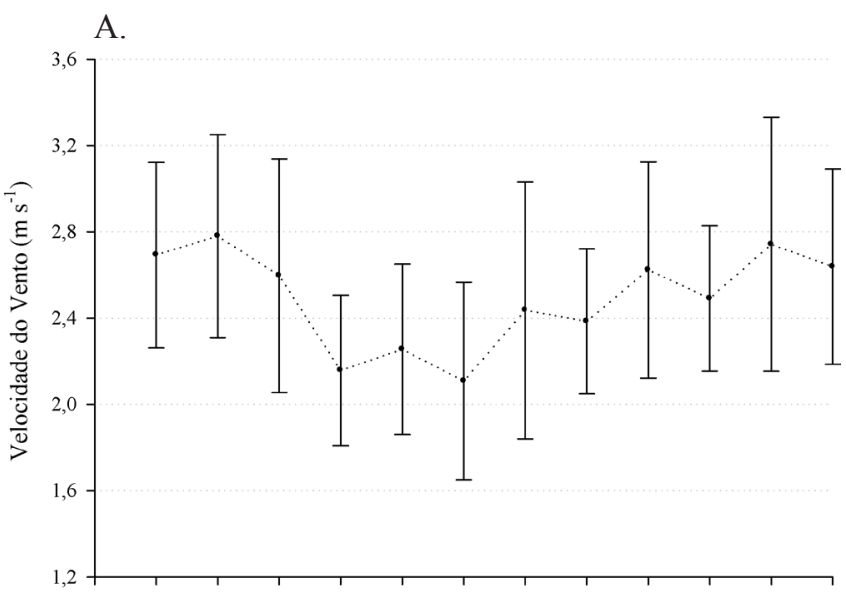

B.

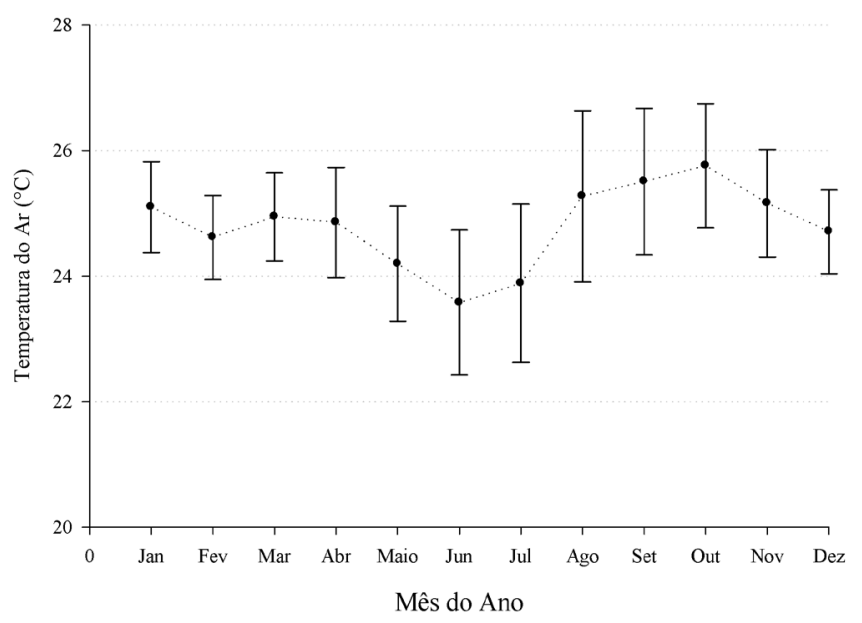

Figura 3. Padrões sazonais dos valores médios mensais e IC (95\%) da velocidade do vento a 9,3 m (A) e temperatura do ar (B) nos anos de 2000 a 2005

médios, o período com maior temperatura do ar foi o secoúmido $\left(25,7 \pm 0,96^{\circ} \mathrm{C}\right)$, enquanto o de menor foi o úmido-seco $\left(24,9 \pm 0,91{ }^{\circ} \mathrm{C}\right)$. A redução nas médias térmicas durante esse período é advinda da penetração de fortes massas de ar frias que atingem a região Norte do Brasil, geralmente nos meses de maio a agosto, conforme elucidado por Culf et al. (1996) e Oliveira et al. (2004).

A umidade específica do ar acompanhou o comportamento da precipitação (Figura 4), com menores valores ocorrendo no período seco $\left(12,9 \pm 0,72 \mathrm{~g} \mathrm{~kg}^{-1}\right)$ e maiores no período úmido $\left(16,4 \pm 0,35 \mathrm{~g} \mathrm{~kg}^{-1}\right)$, no qual o período úmido foi superior em $27 \%$ em relação ao seco. No período seco ocorreram os maiores défices de umidade específica uma vez que a precipitação é menor nessa estação e a temperatura é mais elevada. Em termos médios, o défice de umidade específica foi cerca de 50\% maior no período seco em relação ao úmido.

Os valores de umidade específica do ar aqui apresentados são inferiores aos apresentados por Randow et al. (2004), que encontraram valores médios de 15,8 e 17,5 $\mathrm{g} \mathrm{kg}^{-1}$ no período seco e úmido, respectivamente, ao estudar uma área com cobertura florestal. Essa diferença entre as duas regiões pode ser elucidada pelo fato da aerodinâmica da pastagem ser suave e as inversões de temperatura serem fortes, o que resulta em uma mistura menos eficiente entre a camada acima da superfície e as camadas superiores da atmosfera (Maitelli \& Wright, 1996).

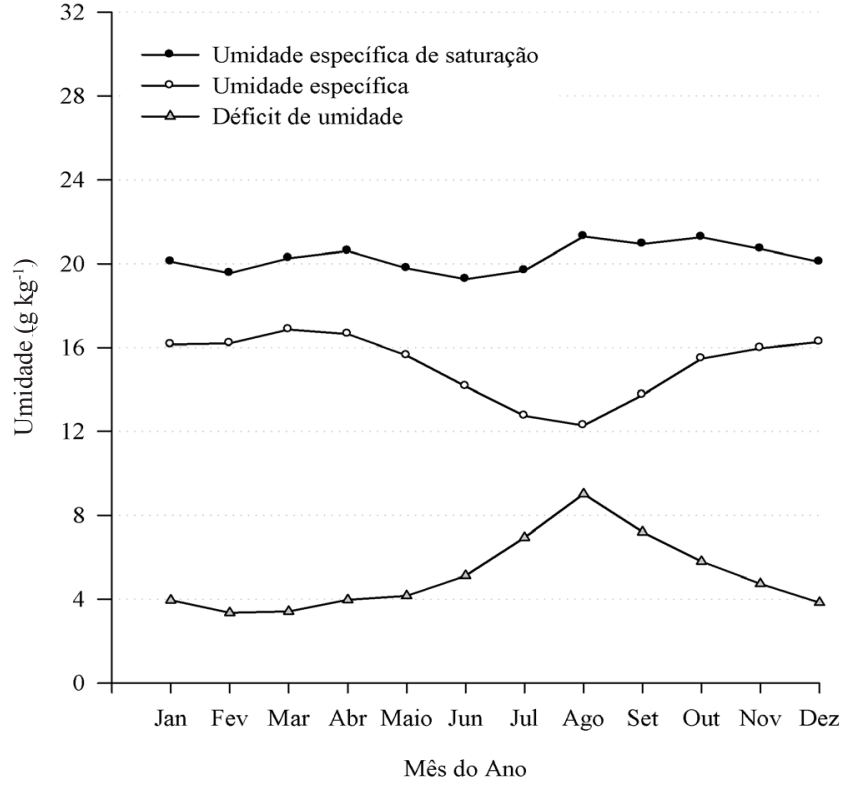

Figura 4. Padrões sazonais dos valores médios mensais da umidade específica de saturação (círculo fechado), umidade específica (círculo aberto) e défice de umidade (triângulo cinza) nos anos de 2000 a 2005

O fechamento do balanço de energia nos quatros períodos do ano pode ser observado na Figura 5 . O período seco apresentou o melhor fechamento (Figura 5C), aproximadamente de $88 \%$ $\left(\mathrm{R}^{2}=0,89\right)$, valor condizente ao encontrado em diversos trabalhos (Rocha et al., 2004; Aguiar et al., 2006; Castellví et al., 2008). O melhor resultado neste período se deve à expressiva ocorrência de dias sem a presença de chuvas visto que os sensores utilizados apresentam um desempenho melhor nessas condições.

Há uma distinção entre os períodos devido, provavelmente, à interferência da pluviosidade nas medidas visto que em muitos casos o Licor-6262 apresentou erros em razão da presença de água na forma líquida nas células do sensor, o que pode explicar os valores mais baixos de fechamento do balanço, comparativamente ao período seco, verificados nos períodos úmido (68\%) e úmido-seco $(66 \%)$.

Apesar do fechamento do balanço de energia apresentar variabilidade de acordo com o ecossistema e com a instrumentação utilizada com resíduo usualmente variando de 0 a 30\% (Twine et al., 2000), os valores encontrados neste estudo, exceto pelo período seco, estão bem abaixo dos obtidos em outros estudos. Randow et al. (2004) observaram um fechamento de $74 \%$ ao analisar o balanço de energia na mesma região estudada e Priante Filho et al. (2004) encontraram um fechamento de $85 \%$ em uma área de pastagem no estado do Mato Grosso. Foken (2008) apresenta uma ampla discussão sobre os problemas no fechamento do balanço de energia.

Devido a esses baixos valores do fechamento de energia, pode-se constatar que ocorreram erros nas medidas de alguns componentes desse balanço. Conforme discutido por Twine et al. (2000) e Randow et al. (2004) podem ocorrer duas formas de se ajustar os dados dos componentes do balanço de energia: (i) ajustando, de forma proporcional e conforme a razão de Bowen (ii) ou descartando simplesmente os dados de calor latente estimando-os como o resíduo do balanço de energia. 
A.

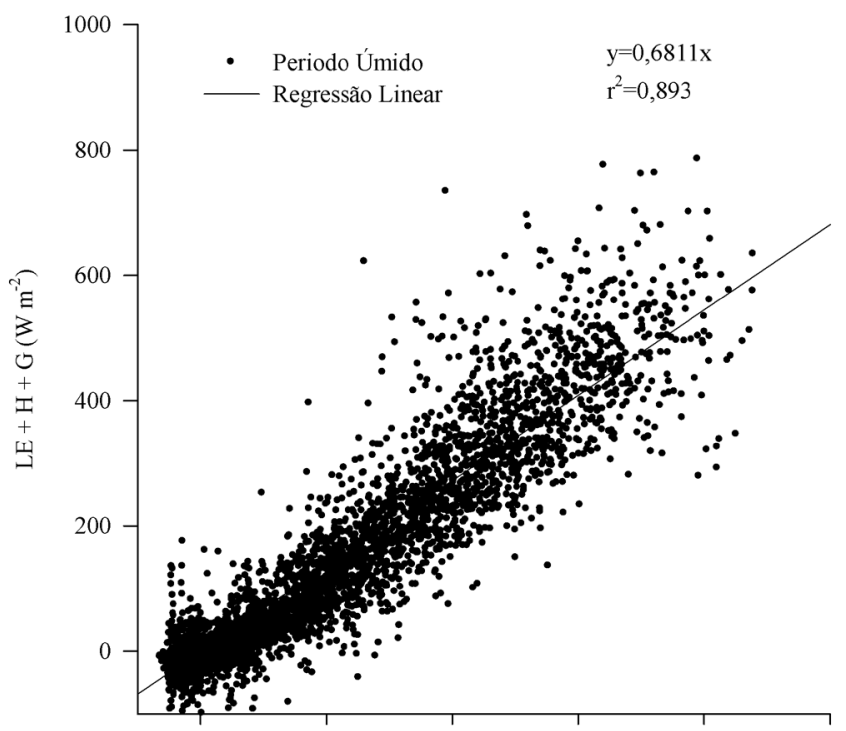

C.

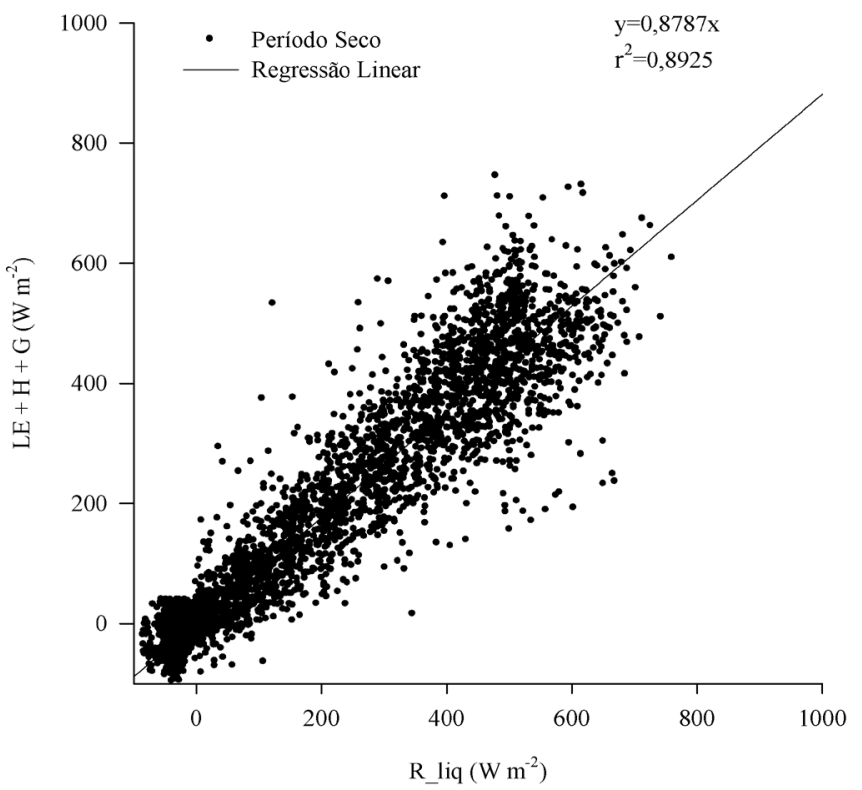

B.

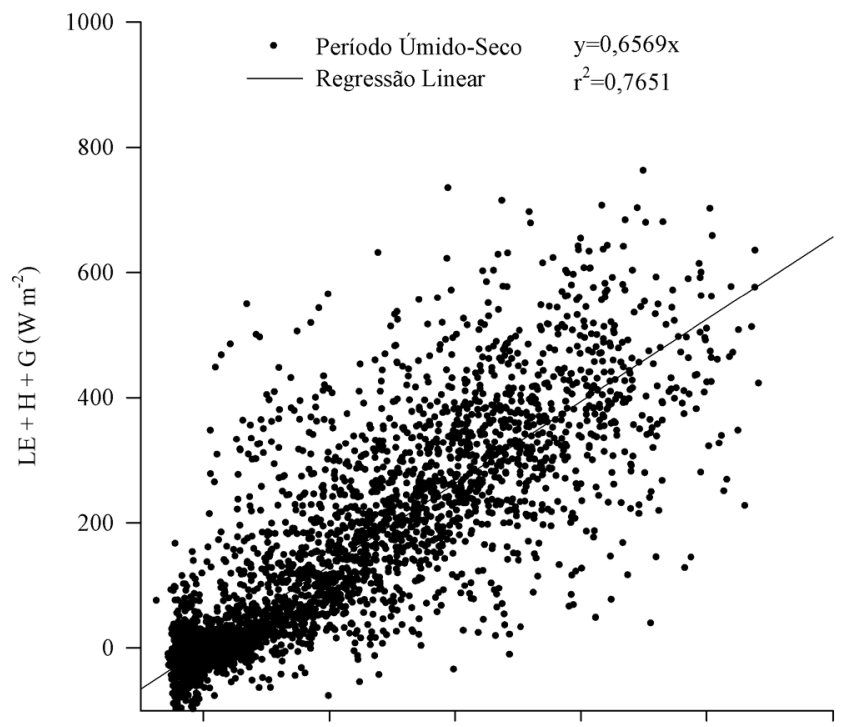

D.

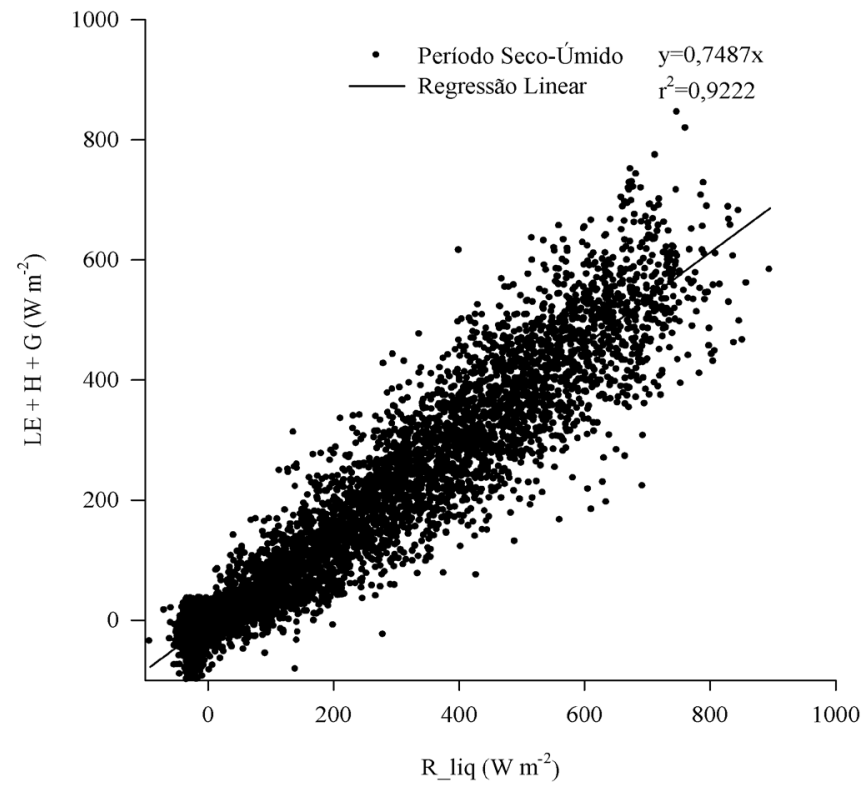

Figura 5. Relação entre a radiação líquida ( $R$ liq) e a soma dos fluxos de calor latente (LE), sensível $(H)$ e de calor no solo $(\mathrm{G})$ no período úmido $(\mathrm{A})(\mathrm{n}=6.646)$, úmido-seco $(\mathrm{B})(\mathrm{n}=5.222)$, seco $(\mathrm{C})(\mathrm{n}=6.967)$ e seco-úmido $(\mathrm{D})$ $(\mathrm{n}=9.883)$ nos anos de 2000 a 2005

Um olhar mais crítico sobre os dados de fluxo de calor conduz à conclusão de que os dados de calor latente estão sendo subestimados uma vez que os dados da radiação líquida e dos fluxos de calor sensível e do solo estão próximos aos encontrados em outros estudos, além de que o $\mathrm{H}$ apresenta uma medida mais precisa pois é calculado apenas através de medidas sônicas. Assim, optou-se por descartar os dados de LE e estimá-los como o resíduo do balanço de energia.

Durante o período de estudo em média $68,94 \pm 3,92 \%$ da energia disponível foram destinados ao LE, $30,70 \pm 2,78 \%$ ao $\mathrm{H}$ e $0,40 \pm 1,03 \%$ ao $\mathrm{G}$; desta forma, a maior quantidade de energia disponível no sistema foi utilizada para o LE, seguida do H (Tabela 2). A partição da R_liq em LE influi diretamente na determinação do ciclo hidrológico, no desenvolvimento da camada limite, no tempo e no clima, influenciando diretamente na precipitação (Andrade et al., 2009).
Tabela 2. Valores médios e IC (95\%) da radiação líquida ( $R$ liq), fluxo de calor latente (LE), fluxo de calor sensível $(\mathrm{H})$ e fluxo de calor no solo $(\mathrm{G})$ nos anos de 2000 a 2005

\begin{tabular}{crr}
\hline \multirow{2}{*}{ Variáveis } & Média & IC \\
\cline { 2 - 3 } $\mathrm{R}_{\text {Bliq }}$ & 117,93 & \\
$\mathrm{LE}$ & 81,30 & $\pm 2,93$ \\
$\mathrm{H}$ & 36,15 & $\pm 5,69$ \\
$\mathrm{G}$ & 0,47 & $\pm 1,18$ \\
\hline
\end{tabular}

O padrão diário médio do $\mathrm{LE}, \mathrm{H}, \mathrm{G}$ e da $\mathrm{R}$ liq nos períodos úmido e úmido-seco está exposto na Figura 6. É perceptível que no período úmido o LE foi superior ao $\mathrm{H}(345 \%)$ apresentando os valores de 96,00 e $27,76 \mathrm{~W} \mathrm{~m}^{-2}$, respectivamente. Um dos fatores principais para a elucidação deste fato é a expressiva 
quantidade de água disponível no solo possibilitando que a maior parte da energia disponível seja destinada à evapotranspiração e uma parte menor, ao aquecimento do ar.

$\mathrm{O}$ período úmido-seco (Figura $6 \mathrm{~B}$ ) apresenta menor pluviosidade do que o úmido, ocasionando uma diminuição média de $21,6 \%$ do LE e aumento nas mesmas proporções $(21,3 \%)$ do $\mathrm{H}$, sinalizando valores médios de 75,20 e $33,66 \mathrm{~W} \mathrm{~m}^{-2}$, respectivamente para LE e H. Por sua vez, o $\mathrm{G}$ apresentou comportamento distinto, com queda média de $-0,36 \mathrm{~W} \mathrm{~m}^{-2}$ para $-0,83 \mathrm{~W} \mathrm{~m}^{-2}$, o que representa uma liberação de energia do solo para a atmosfera adjacente.

O padrão diário médio do $\mathrm{LE}, \mathrm{H}, \mathrm{G}$ e da $\mathrm{R}$ liq nos períodos seco e seco-úmido está exposto na Figura 7. É possível notar que o LE e o $\mathrm{H}$ ficaram bem próximos no período seco (Figura

A.

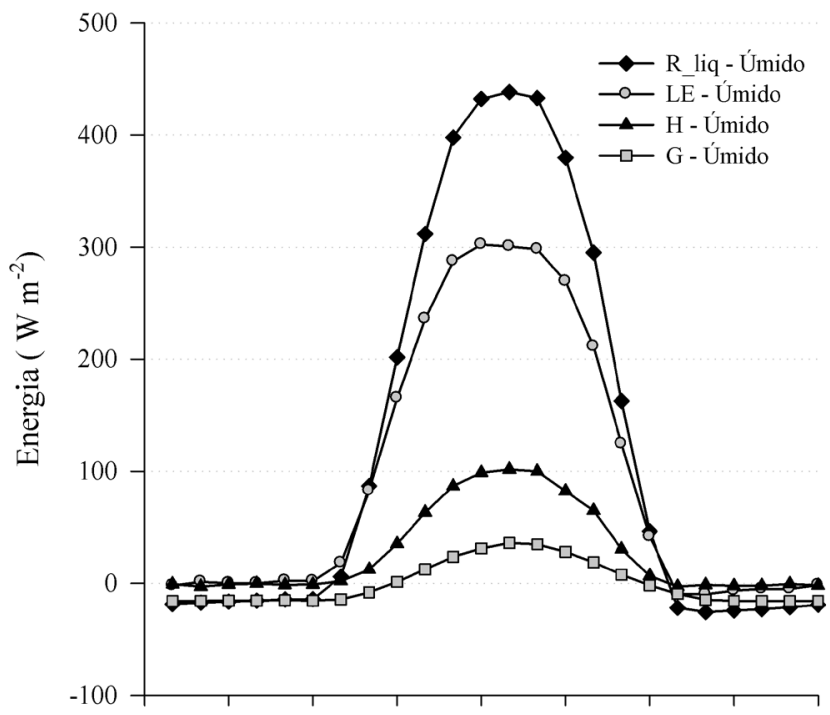

B.

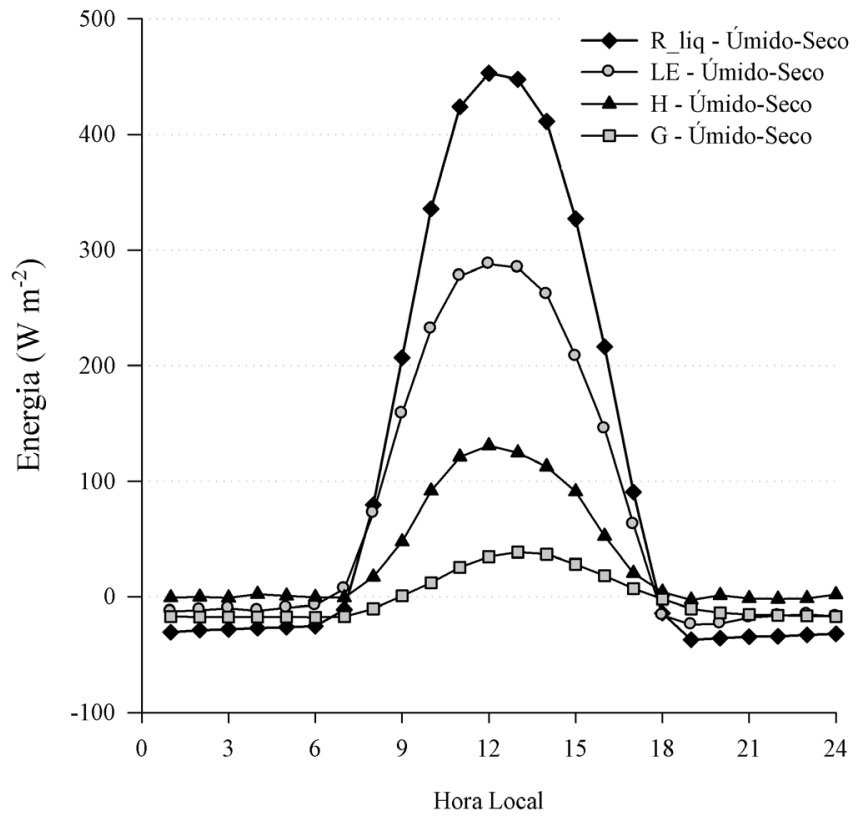

Figura 6. Padrão diário médio dos fluxos de calor latente (LE), sensível $(H)$, de calor no solo $(G)$ e da radiação líquida $(R$ liq) no período úmido $(A)$ e úmido-seco (B) nos anos de 2000 a 2005
7A) devido a um aumento considerável de $\mathrm{H}$, fato que ocorre em razão do défice de precipitação característico dessa época do ano na região, ocasionando estresse hídrico na gramínea Brachiaria brizantha o que diminui a abertura dos estômatos, a fim de evitar a perda de água em demasia.

Quando os estômatos estão abertos durante as trocas de dióxido de carbono e de oxigênio com a atmosfera, também é permitida a passagem de vapor de água processo conhecido como transpiração. Contudo, a eficiência desse processo depende de diversos fatores, sendo um dos principais a disponibilidade de água no solo que, ao apresentar um défice, ocasiona o fechamento ou diminuição da abertura dos estômatos, a fim de reduzir a perda de água (Jacobsen et al., 2009), ocasionando diminuição da evapotranspiração (calor latente, em termos de energia).

A.

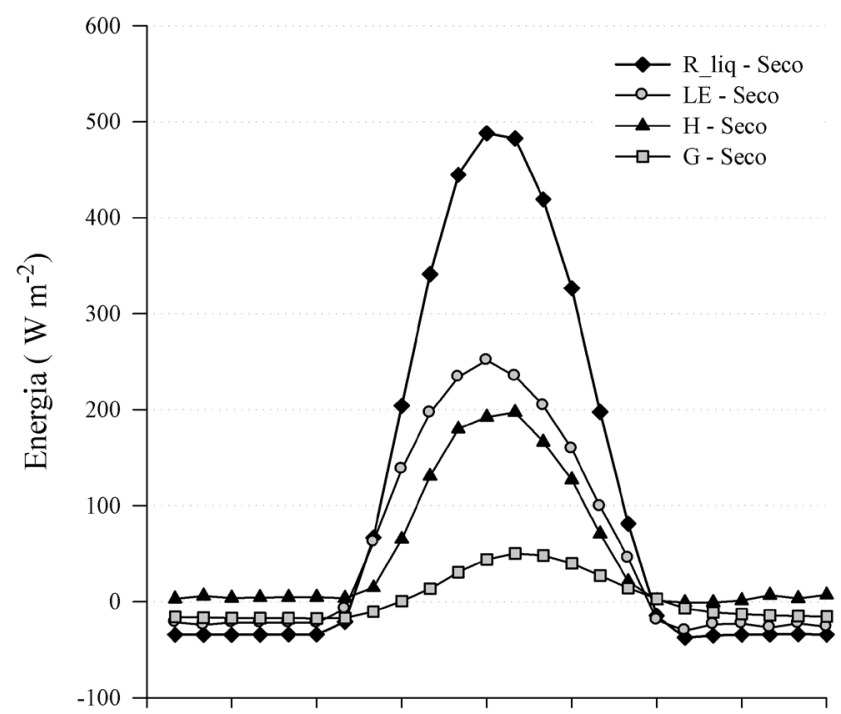

B.

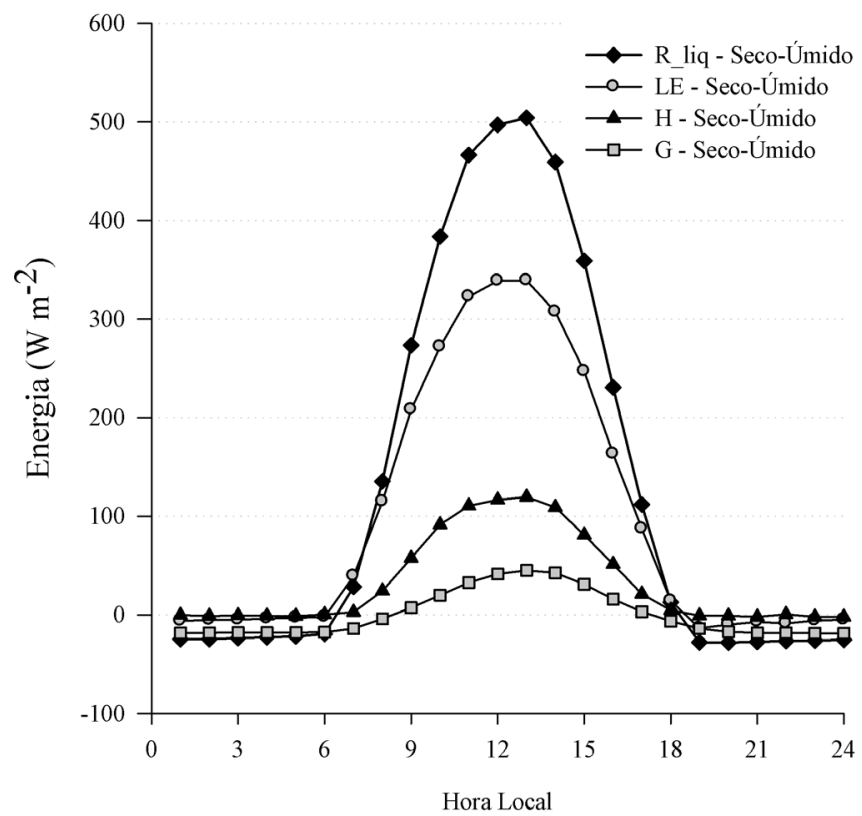

Figura 7. Padrão diário médio dos fluxos de calor latente (LE), sensível $(H)$, de calor no solo $(G)$ e da radiação líquida ( $\mathrm{R}$ liq) no período seco $(\mathrm{A})$ e seco-úmido (B) nos anos de 2000 a 2005 
Com a redução da evapotranspiração, uma maior parcela de R_liq ficará disponível. Consequentemente, ocorrerá um aumento do $\mathrm{H}$ destinado ao aquecimento da atmosfera, razão pela qual os valores de mais elevados de $\mathrm{H}$ são encontrados durante o período seco. O mesmo comportamento foi observado por Pezzopane \& Pedro Júnior (2003) e por Santos et al. (2009) ao analisar o balanço de energia em plantações de uva e banana, respectivamente.

No período seco-úmido (Figura 7B) começam a ocorrer as primeiras chuvas, o que aumenta consideravelmente a concentração de água no solo. A partir deste evento uma parcela maior da energia volta a ser destinada ao fluxo de calor latente. É perceptível que houve um aumento do LE $(80,8 \%)$, passando de 54,85 para $92,17 \mathrm{~W} \mathrm{~m}^{-2}$ além de queda do $\mathrm{H}(64,3 \%)$, passando de 50,63 para $32,54 \mathrm{~W} \mathrm{~m}^{-2}$ e do $\mathrm{G}(1471 \%)$, passando de 2,9 para $0,20 \mathrm{~W} \mathrm{~m}^{-2}$ em relação ao período seco.

Em suma, o sítio estudado apresentou diferenças no particionamento de energia no sistema, durante os quatro períodos do ano.

Resultados de alguns estudos em área de floresta que dista $100 \mathrm{~km}$ da área de pastagem estão apresentados na Tabela 3, visando evidenciar prováveis efeitos decorrentes das mudanças no uso do solo.

Tabela 3. Valores médios dos anos de 2000 a 2005 da radiação líquida ( $R_{-}$liq), fluxos de calor latente (LE) e sensível $(\mathrm{H})$ em área de pastagem (FNS), nos períodos úmido, úmido-seco, seco e seco-úmido e de floresta (Randow et al., 2004; Aguiar et al., 2006), nos períodos úmido e seco

\begin{tabular}{|c|c|c|c|c|}
\hline $\begin{array}{c}\text { Variáveis } \\
\left(\mathrm{W} \mathrm{m}^{-2}\right)\end{array}$ & Período & $\begin{array}{l}\text { von } \\
\text { Randow et } \\
\text { al. (2004) }\end{array}$ & $\begin{array}{l}\text { Aguiar et } \\
\text { al. }(2006)\end{array}$ & FNS \\
\hline \multirow{5}{*}{ R_liq } & Úmido & 136,1 & 134,3 & 123,39 \\
\hline & Úmido-seco & - & - & 108,03 \\
\hline & Seco & 146,9 & 131,6 & 108,38 \\
\hline & Seco-úmido & - & - & 131,91 \\
\hline & Úmido & 104,5 & 115,5 & 96,00 \\
\hline \multirow[t]{2}{*}{ LE } & Úmido-seco & - & - & 75,20 \\
\hline & Seco & 108,6 & 92,9 & 54,85 \\
\hline \multirow{5}{*}{$\mathrm{H}$} & Seco-úmido & - & - & 99,17 \\
\hline & Úmido & 31,6 & 17,0 & 27,76 \\
\hline & Úmido-seco & - & - & 33,67 \\
\hline & Seco & 38,3 & 37,1 & 50,63 \\
\hline & Seco-úmido & - & - & 32,54 \\
\hline
\end{tabular}

Ao comparar essa área de pastagem com ecossistemas de floresta é visível que a pastagem apresenta maior vulnerabilidade às perdas hídricas apresentando-se mais suscetível a variações sazonais no particionamento do saldo de energia, principalmente nos meses com menores níveis de precipitação.

Ao analisar apenas os dados da FNS e comparar o período seco com o período úmido, observa-se que o fluxo de calor latente apresentou queda de $42,86 \%$, passando de 96,00 $\mathrm{W} \mathrm{m}{ }^{-2}$ no período úmido para $54,85 \mathrm{~W} \mathrm{~m}^{-2}$ no seco. O fluxo de calor sensível teve um aumento de $82,4 \%$ passando de 27,76 $\mathrm{W} \mathrm{m}{ }^{-2}$ no período úmido para $50,63 \mathrm{~W} \mathrm{~m}^{-2}$ no período seco, fato explicado pela menor ocorrência de precipitação que acarreta uma elevação considerável da energia que passa a ser destinada ao $\mathrm{H}$.
Utilizando uma média entre os valores encontrados por Randow et al. (2004) e Aguiar et al. (2006) para o ecossistema de floresta, nota-se que a radiação líquida apresenta uma diferença média entre os dois ecossistemas - floresta e pastagem - nos períodos úmido e seco, respectivamente, de 9,6 e 28,5\%, nos quais essa diferença evidencia que a área de floresta dispõe de mais energia para os seus processos.

Desse total de R_liq disponível é possível observar que, embora ambos os ecossistemas particionem mais $\mathrm{R}$ liq em LE, a floresta apresenta taxas maiores de LE $(81,39 \%$ no período úmido e $74,96 \%$ no período seco) e menores de $\mathrm{H}(17,9 \%$ no período úmido e $28,1 \%$ no período seco), que a área de pastagem, que apresenta uma partição da radiação líquida nos períodos úmido e seco de, respectivamente, 78,0 e 50,6\% para o LE e 22,5 e $46,71 \%$ para o $\mathrm{H}$.

A diferença de particionamento dos fluxos nos diferentes ecossistemas torna-se maior durante o período seco evidenciando uma vulnerabilidade maior da pastagem às alterações sazonais, quando então a maior parcela da energia passa a ser destinada para o aquecimento do ar (em forma de $\mathrm{H}$ ), em detrimento do LE.

Tal fato pode ocorrer devido as árvores da Floresta Amazônica serem melhor adaptadas à diminuição das chuvas possuindo raízes profundas capazes de atingir o lençol freático nas camadas inferiores do solo (Negrón-Juaréz et al., 2007), de modo que a evapotranspiração na área de floresta é pouco afetada nos meses mais secos, diferente do que ocorre após sua substituição por pastagem, cujas raízes das gramíneas atingem apenas as camadas superiores do solo, mais susceptíveis às perdas hídricas por evaporação.

Esses resultados sugerem diferenças relevantes na magnitude e na variação sazonal do particionamento de energia entre pastagens e florestas e estão de acordo com estudos realizados por Priante Filho et al. (2004). Deste modo, ao ocorrer o desflorestamento, acontecem principalmente o aumento do uso de energia para $\mathrm{H} \mathrm{e}$, consequentemente, o acréscimo da temperatura do ar e a diminuição da umidade disponível no sistema, ocasionando uma alteração no equilíbrio energético da região.

Tendo em vista essas mudanças é perceptível, para muitos especialistas, que o equilíbrio do planeta está se alterando (Fearnside, 2009), sendo que as atividades antrópicas, como as queimadas e o desflorestamento, têm sido apontadas como as principais causas.

\section{Conclusões}

1. Os resultados denotaram variações nos componentes do balanço de energia nos diferentes períodos do ano em uma área de pastagem no sudoeste da Amazônia, evidenciando maior vulnerabilidade dessa vegetação às alterações sazonais.

2. O período seco apresentou melhor fechamento do balanço de energia, de aproximadamente $88 \%$. O período que teve o menor fechamento foi o úmido, com $68 \%$.

3. Os resultados da partição da radiação líquida entre ecossistemas de pastagem e floresta evidenciaram um consequente aumento na variação sazonal e nas taxas de aquecimento da superfície do solo e do ar adjacente na 
pastagem, ressaltando a importância da preservação das coberturas vegetais naturais na região amazônica.

\section{Agradecimentos}

Ao Programa LBA e à Universidade Federal de Rondônia (UNIR) pela oportunidade de estudo e suporte logístico; à Fundação Amazônica de Defesa da Biosfera (FDB), ao Conselho Nacional de Desenvolvimento Científico e Tecnológico (CNPq) e à Coordenação de Aperfeiçoamento de Pessoal de Nível Superior (CAPES) pelas bolsas concedidas; aos técnicos do Instituto Chico Mendes de Conservação da Biodiversidade (ICMBio) pelo suporte nas coletas e aos alunos bolsistas da UNIR - Campus de Ji-Paraná pela coleta e processamento dos dados.

\section{Literatura Citada}

Aguiar, R. G.; Randow, C. V.; Priante Filho, N.; Manzi, A. O.; Aguiar, L. J. G.; Cardoso, F. L. Fluxos de massa e energia em uma floresta tropical no sudoeste da Amazônia. Revista Brasileira de Meteorologia, v.21, p.248-257, 2006.

Andrade, N. L. R.; Aguiar, R. G.; Sanches, L.; Alves, E. C. R. F.; Nogueira, J. de S. Partição do saldo de radiação em áreas de floresta amazônica e floresta de transição Amazônia-Cerrado. Revista Brasileira de Meteorologia, v.24, p.346-355, 2009.

Artaxo, P.; Gatti, L. V.; Leal, A. M. C.; Rizzo, L. V.; Procópio, A. S. Química atmosférica na Amazônia: A floresta e como emissões de queimadas controlando uma composição da atmosfera amazônica. Acta Amazonica, v.35, p.185-198, 2005.

Castellví, F.; Snyder, R. L.; Baldocchi, D. Surface energybalance closure over rangeland grass using the eddy covariance method and surface renewal analysis. Agriculture Ecosystems and Environment, v.148, p.147-160, 2008.

Correia, F. W. S. Impacto das modificações da cobertura vegetal no balanço de água na Amazônia: Um estudo com modelo de circulação geral da atmosfera (MCGA). Revista Brasileira de Meteorologia, v.21, 153-167, 2006.

Costa, F. R.; Feitosa, J. R.; Fisch, G.; Souza, S. S.; Nobre, C. A. Variabilidade diária da precipitação em regiões de floresta e pastagem na Amazônia. Acta Amazônica,v.28, p.395-407, 1998.

Culf, A. D.; Esteves, J. L.; Marques, F. O.; da Rocha, H. R. Radiation, temperature and humidity over Forest and pasture in Amazonia. In: Gash, J.; Nobre, A. C.; Roberts, J. M.; Victoria, R. Amazon deforestation and climate. Chichester: John Wiley and sons, 1996. Cap.5, p.175-192.

Dias, M. A. F. S.; Cohen, J. C. P.; Gandu, A. W. Interações entre nuvens, chuvas e a biosfera na Amazônia. Acta Amazônica, v.35, p.215-222, 2005.

Elbers, J. A. Eddy correlation system: user manual version 2.0. Wageningen: Alterra, The Netherlands, 1998. 39p.

Ewers, R. M.; Laurance, W. F.; Souza, C. M. Temporal fluctuations in Amazonian deforestation rates. Acta Amazônica, v.35, p.303-310, 2008.

Fearnside, P. M. Vulnerabilidade da floresta amazônica perante as mudanças climáticas. Oecologia Brasiliensis, v.13, p.609-618, 2009.
Foken, T. The energy balance closure problem: An overview. Ecological Applications, v.18, p.1351-1367, 2008.

IDARON - Agência de Defesa Sanitária Agrosilvopastoril do Estado de Rondônia. Informativo técnico do rebanho bovino de Rondônia. Porto Velho: IDARON, 2008.2p.

Jacobsen, S. E.; Liu, F.; Jensen, R. C. Does root-sourced ABA play a role for regulation of stomata under drought in quinoa (Chenopodium quinoa Willd). Scientia Horticulturae, v.122, p.281-287, 2009.

Keller, M.; Alencar, A.; Asner, G. P.; Braswell, B.; Bustamante, M.; Davidson, E.; Feldpausch, T.; Fernandes, E.; Goulden, M. L.; Kabat, P.; Kruijt, B.; Luizão, F.; Miller, S.; Markewitz, D.; Nobre, A. D.; Nobre, C. A.; Priante Filho, N.; Rocha, H. R.; Dias, P. L. S.; Randow, C. von; Vourlitis, G. Ecological research in the large-scale biosphere-atmosphere experiment in Amazonia: Early results. Ecological Applications, v.14, p.S3-S16, 2004.

Machado, L. A. T.; Laurent, H.; Dessay, N.; Miranda, I. Variabilidade sazonal e diurna da convecção sobre a bacia amazônica: Uma comparação dos diferentes tipos de vegetação. Theoretical and Applied Climatology, v.78, p.61-77, 2004.

Maitelli, G. T.; Wright, I. R. The climate of a riverside city in the Amazon Basin: Urban-rural differences in temperature and humidity. In: Gash, J.; Nobre, A. C.; Roberts, J. M.; Victoria, R. Amazon deforestation and Climate. Chichester: John Wiley and Sons, 1996. Cap.11, p.193-206.

Negrón-Juaréz, R. I.; Hodnett, M. G.; Fu, R.;Goulden, M. L.; Randow, C. von. Control of dry season evapotranspiration over the Amazonian forest as inferred from observations at a Southern Amazon forest site, Journal of Climate, v.20, p.2827-2839. 2007.

Oliveira, P. J.; Rocha, E. J. P. da; Fisch, G.; Kruijt, B.; Ribeiro, J. B. M. Efeitos de um evento de friagem nas condições meteorológicas na Amazônia: Um estudo de caso. Acta Amazonica, v.34, p.613-619, 2004.

Pezzopane, J. R. M.; Pedro Júnior, M. J. Balanço de energia em vinhedo de niagara rosada. Bragantia, v.62, p.155-161, 2003.

Priante Filho, N.; Vourlitis, G. L.; Hayashi, M. M. S.; Nogueira, J. S.; Campelo, J.; Nunes, P. C.; Souza, L. S. E.; Couto, E. G.; Hoeger, W.; Raiter, F.; Trienweiler, J. L.; Miranda, E. J.; Priante, P. C.; Fritzen, C. L.; Lacerda, M.; Pereira, L. C.; Biudes, M. S.; Suli, G. S.; Shiraiwa, S.; Paulo, S. R.; Silveira, M. Comparison of the mass and energy exchange of a pasture and a mature transitional tropical forest of a Southern Amazon bazinduring the wet-dry season transition. Global Change Biology, v.10, p.863-876, 2004.

Randow, C. von; Manzi, A. O.; Kruijt, B.; Oliveira, P. J.; Zanchi, F. B.; Silva, R. L.; Hodnett, M. G.; Gash, J. H. C.; Elbers, J. A.; Waterloo, M. J.; Cardoso, F. L.; Kabati, P. Comparative measurements and seasonal variations in energy and carbon exchange over forest and pasture in South West Amazonia. Theorical and Applied Climatology, v.especial, p.1-22, 2004.

Rocha, H. R.; Goulden, M. L.; Miller, S. D.; Menton, M. C.; Pinto, L.D. V. O.; Freitas, H. C.; Figueira, A. M. S. Seasonality of water and heat fluxes over a tropical Forest in eastern Amazonia. Ecological Applications, v.14, p.2232, 2004. 
Santos, C. A.; Silva, B. B. da; Rao, T. V. R.; Neale, C. M. U. Energy balance measurements over a banana orchard in the semiarid region in the Northeast of Brazil. Pesquisa Agropecuária Brasileira, v.44, p.1365-1376, 2009.

Tanaka N.; Kume, T.; Yoshifuji, N.; Tanaka, K.; Takizawa, H.; Shiraki, K.; Tantasirin, C. A review of evapotranspiration estimates from tropical forests in Thailand and adjacent regions. Agriculture Ecosystems \& Environment, v.148, p.807-819, 2008.
Twine, T. E.; Kustas, W. P.; Norman, J. M.; Cook, D. R.; Houser, P. R.; Meyers, T. P.; Prueger, J. H.; Starks, P. J.; Wesely, M. L. Correctingeddy-covariance flux underestimates over a grassland. Agricultural and Forest Meteorology, v.103, p.279-300, 2000.

Webler, A. D.; Aguiar, R. G.; Aguiar, L. J. G. Características da precipitação em área de floresta primária e área de pastagem no Estado de Rondônia. Revista Ciência e Natura, v.especial, p.55-58, 2007. 